
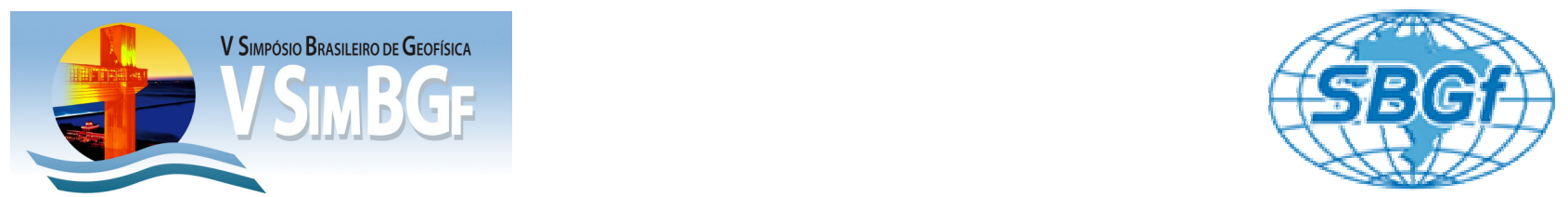

\title{
Simulação de reflexões primárias e múltiplas usando aproximação paraxial de tempos de trânsito CRS de $4^{a}$ ordem.
}

Ordilei Pantoja e Silva (UFPA), Pedro Andrés Chira Oliva (UFPA) (*), João C. R. Cruz (UFPA)

Copyright 2012, SBGf - Sociedade Brasileira de Geofísica

Este texto foi preparado para a apresentação no V Simpósio Brasileiro de Geofísica, Salvador, 27 a 29 de novembro de 2012. Seu conteúdo foi revisado pelo Comitế Técnico do V SimBGf, mas não necessariamente representa a opinião da SBGf ou de seus associados. É proibida a reprodução total ou parcial deste material para propósitos comerciais sem prévia autorização da SBG.

\section{Resumo}

Aproximações de tempos de trânsito utilizadas no empilhamento sísmico de eventos de reflexão ou difração são importantes para o imageamento e a inversão de dados sísmicos. No final da década de 90 vários métodos de empilhamento sísmico apresentaram diversas formas destas aproximações que usam mais de um parâmetro ou atributo no empilhamento e permitem usar configurações sísmicas arbitrárias. O método CRS (Common-Reflection-Surface) pertence a este grupo e simula seções sísmicas ZO (zero-offset) ou de afastamento-nulo (AN) a partir de dados sísmicos de cobertura múltipla. Neste trabalho a expansão de Taylor da aproximação de tempos de trânsito CRS de $2^{\text {a }}$ ordem, também, conhecida como aproximação CRS de $4^{\text {a }}$ ordem, foi testada em dados sintéticos. A finalidade deste teste foi verificar sua habilidade e/ou eficiência na simulação de reflexões primárias e/ou múltiplas com afastamento fonte-receptor nulo, e realizar uma comparação com a aproximação CRS de $2^{\underline{a}}$ ordem no empilhamento sísmico. Ambas as aproximações dependem do mesmo número de parâmetros utilizados pelo método CRS. Porém, a aproximação CRS de $4^{\text {a }}$ ordem tem mostrado um bom desempenho na simulação de seções sísmicas de afastamento-nulo para o imageamento sísmico de reflexões múltiplas.

\section{Introdução}

A simulação de seções sísmicas zero-offset (ZO) ou de afastamento (fonte-receptor) nulo a partir de dados sísmicos de cobertura múltipla conhecida como empilhamento sísmico é um método de imageamento padrão que é freqüentemente utilizado no processamento sísmico para reduzir a quantidade de dados e melhorar a razão sinal/ruído. O empilhamento sísmico é realizado ao longo de aproximações de tempos de trânsito que depende de um ou mais parâmetros.

O imageamento sísmico objetiva gerar a melhor imagem possível das estruturas geológicas complexas em subsuperfície a partir de dados sísmicos de cobertura múltipla. No final da década de 90 apareceram diversos métodos de imageamento como uma nova alternativa ou para generalizar o método de empilhamento CMP. Estes métodos são referidos na literatura geofísica como métodos independentes do macro-modelo de velocidades (HUBRAL, 1999). Pois em vez de trabalhar somente com um único parâmetro ou a velocidade de empilhamento (método CMP), os novos métodos fornecem dois ou três parâmetros para cada ponto da seção ZO simulada. O método CRS (Common-reflection-surface) (GARABITO et al., 2001; Jäger et al., 2001; Müller et al., 1998; Mann et al., 1999, entre outros)faz parte deste grupo de métodos. A aproximação de tempos de trânsito CRS define uma superfície de empilhamento para cada amostra na seção sísmica ZO a ser simulada. Desta maneira somam-se as amplitudes dos traços sísmicos nos dados de cobertura múltipla ao longo de uma superfície definida pela aproximação de tempos de trânsito hiperbólica na forma derivada por Tygel et al. (1997). A aproximação de tempos de trânsito CRS convencional é de $2^{\mathrm{a}}$ ordem e depende de três parâmetros: o ângulo de emergência do raio de incidência normal e as curvaturas de frente de onda de duas ondas hipotéticas chamadas onda NormalIncidence-Point (NIP) e onda Normal (N) introduzidas por Hubral (1983).

Na busca de uma aproximação de tempos de trânsito que melhore a aproximação CRS de $2^{\mathrm{a}}$ ordem, Höcht et al. (1999) consideraram a reflexão de uma interface como um conjunto contínuo de elementos de reflexão circular que osculam o refletor original. Eles derivaram uma expansão de Taylor da aproximação CRS de $2^{\underline{a}}$ ordem denominado como a aproximação CRS de $4^{\underline{a}}$ ordem. Esta nova aproximação é descrita com o mesmo número de parâmetros da aproximação anterior ou aproximação CRS convencional.

Cabral (2002) realizou a simulação de reflexões múltiplas utilizando a aproximação de tempos de trânsito CRS de $2^{\text {a }}$ ordem. Os resultados mostraram um bom desempenho desta aproximação na simulação de uma seção ZO observando-se um posicionamento correto dos eventos e a preservação da forma do pulso da fonte. Desta maneira o método CRS realça as reflexões múltiplas contidas nos dados sísmicos, além de identificar esses eventos.

Chira-Oliva et al. (2003) revisaram a derivação da aproximação CRS de $4^{\mathrm{a}}$ ordem e discutiram as primeiras comparações para diversas configurações sísmicas considerando a aproximação CRS de $2^{\mathrm{a}}$ ordem. Para esta comparação eles consideraram dados sintéticos e sugeriram que esta nova aproximação pode fornecer uma aproximação melhor para os tempos de trânsito verdadeiros de eventos de reflexão ou difração que a aproximação CRS convencional.

Chira-Oliva et al. (2008) testaram a aproximação CRS de $4^{\mathrm{a}}$ ordem em modelos com dados sintéticos para simular seções ZO. Eles consideraram dados com grandes afastamentos e obtiveram bons resultados a partir desta nova aproximação quando comparada com a aproximação CRS convencional.

Chira-Oliva et al. (2010) testaram a aproximação CRS de $4^{\underline{a}}$ ordem para simular seções sísmicas ZO. Eles 
utilizaram dados sintéticos com ruído e dados reais da Bacia do Tacutu (Brasil) e mostraram uma boa performance da expressão proposta comparada à aproximação CRS convencional.

$O$ presente trabalho tem como objetivo analisar 0 desempenho da aproximação de tempos de trânsito CRS de $4^{a}$ ordem para simulação de eventos de reflexão primária e/ou múltiplas simétricas na configuração $Z O$ neste caso foram considerados dados sintéticos. A nova aproximação tem mostrado um bom desempenho para simulação de seções $Z O$ com eventos de reflexões primárias e múltiplas simétricas.

\section{Método do empilhamento CRS 2-D}

O método de empilhamento CRS permite simular seções sísmicas de afastamento-nulo (AN). Este método soma as amplitudes dos traços sísmicos ao longo de uma superfície construída a partir da aproximação de tempos de trânsito hiperbólica conhecida também como aproximação CRS de $2^{\underline{a}}$ ordem (Tygel et al, 1997; Schleicher et al., 1993), atribuindo-se o resultado ao ponto $P_{0}\left(x_{0}, t_{0}\right)$ da seção ZO a ser simulada (Figura 1). A expansão de Taylor da aproximação de tempos de trânsito CRS de $2^{\mathrm{a}}$ ordem também conhecida como aproximação de tempos de trânsito CRS de $4^{\text {a }}$ ordem foi proposta por Höcht et al. (1999). A finalidade desta expansão era a busca de uma aproximação de tempo de trânsito mais exata.

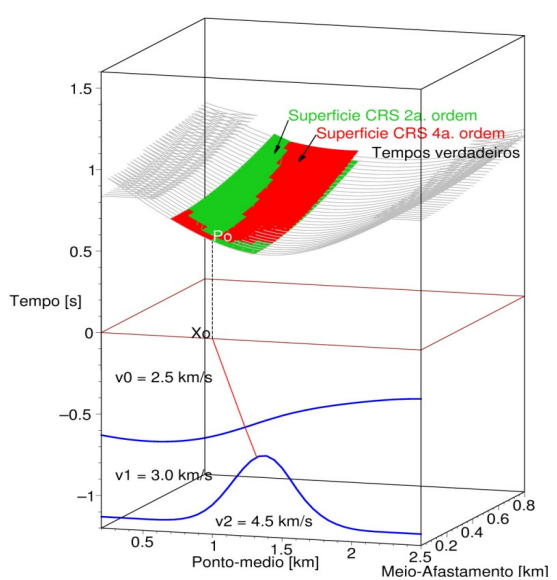

Figura 1 - Parte inferior (frontal): Modelo 2-D constituído por duas camadas sob um semi-espaço cuja interface é similar a um domo. Parte superior: curvas de tempos de trânsito ZO dos dados pré-empilhados (linhas cor cinza) e as superfícies CRS de $2^{\text {a }}$ ordem (superfície cor verde) e de $4^{a}$ ordem (superfície cor vermelha), respectivamente.

Esta expansão esta baseada na construção do tempo de trânsito exato para um meio não homogêneo onde eles consideraram uma onda emergente cuja frente de onda é circular e definida pelos mesmos parâmetros da aproximação CRS de $2^{\text {a }}$ ordem. Esta onda propaga-se com velocidade constante $v_{0}$ próxima à superfície e é expressa por (Höcht et al., 1999):

$$
\begin{aligned}
& t_{4}^{2}\left(x_{m}, h\right)=t_{2, r e f}^{2}\left(x_{m}, h\right)+\frac{\cos ^{2} \beta_{0}}{v_{0}^{2}}\left[A\left(x_{m}-x_{0}\right) h^{2}+\right. \\
& \left.B\left(x_{m}-x_{0}\right)^{3}+C\left(x_{m}-x_{0}\right)^{4}+D\left(x_{m}-x_{0}\right)^{2} h^{2}+E h^{4}\right]
\end{aligned}
$$

sendo

$t_{2, r t f}\left(x_{m}, h\right)=t_{0}+\frac{2 \operatorname{sen} \beta_{0}}{v_{0}}\left(x_{m}-x_{0}\right)+\frac{\cos ^{2} \beta_{0}}{v_{0}}\left[K_{N}\left(x_{m}-x_{0}\right)^{2}+K_{N i p} h^{2}\right]$

$A=2 K_{N I P} \operatorname{sen} \beta_{0}\left[2-2 v_{0} t_{0} K_{N}-v_{0} t_{0} K_{N I P}\right]$,

$B=2 K_{N} \operatorname{sen} \beta_{0}\left[2-2 v_{0} t_{0} K_{N}\right]$,

$C=K_{N}^{2}\left[5 \cos ^{2} \beta_{0}-4\right]\left[1-v_{0} t_{0} K_{N} / 2\right]$,

$D=K_{N I P}\left\{2 v_{0} t_{0}\left[3-4 \cos ^{2} \beta_{0}\right] K_{N}^{2}\right.$

$\left.+K_{N}\left[4-5 \cos ^{2} \beta_{0}\right]\left[-2+v_{0} t_{0} K_{N I P}\right]-2 K_{N I P} \operatorname{sen}^{2} \beta_{0}\left[2-v_{0} t_{0} K_{N I P}\right]\right\}$, $E=K_{N I P}^{2}\left[2 v_{0} t_{0} K_{N} \operatorname{sen}^{2} \beta_{0}-\left(v_{0} t_{0} K_{N I P} \cos ^{2} \beta_{0} / 2\right)+\cos ^{2} \beta_{0}\right]$.

\section{Resultados}

Com a finalidade de testar ambas as aproximações de empilhamento CRS ( $2^{\underline{a}}$ e $4^{\text {a }}$ ordem) em relação ao seu potencial para simular eventos de reflexões primárias e/ou múltiplas foram considerados dois modelos sintéticos.

\section{Modelo I}

O primeiro modelo 2-D considerado neste estudo está constituído por duas camadas homogêneas sob um semiespaço e separadas por interfaces curvas e suaves (Figura 2). As velocidades para cada camada, desde o topo até a base, são: $2.5 \mathrm{~km} / \mathrm{s}, 3.5 \mathrm{~km} / \mathrm{s}$ e $5.5 \mathrm{~km} / \mathrm{s}$. As dimensões do modelo são: $4 \mathrm{~km}$ de comprimento por 3,0 $\mathrm{km}$ de profundidade. A simulação de aquisição foi realizada considerando uma linha horizontal.

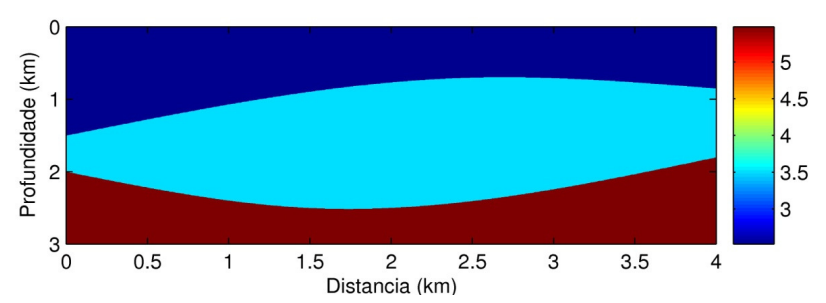

Figura 2 - Modelo 2-D constituído por duas camadas separadas com interfaces curvas e suaves sob um semiespaço.

Baseado neste modelo foi gerado o conjunto de dados sintéticos de reflexão de cobertura múltipla utilizando o algoritmo de traçamento de raio, SEIS88 (Cerveny e Psensik, 1988). Os dados não contêm ruído e foram gerados utilizando a configuração common-shot (CS) ou de tiro comum. O mínimo e máximo afastamento foram $0.6 \mathrm{~km}$ e $2.9 \mathrm{~km}$, respectivamente. 


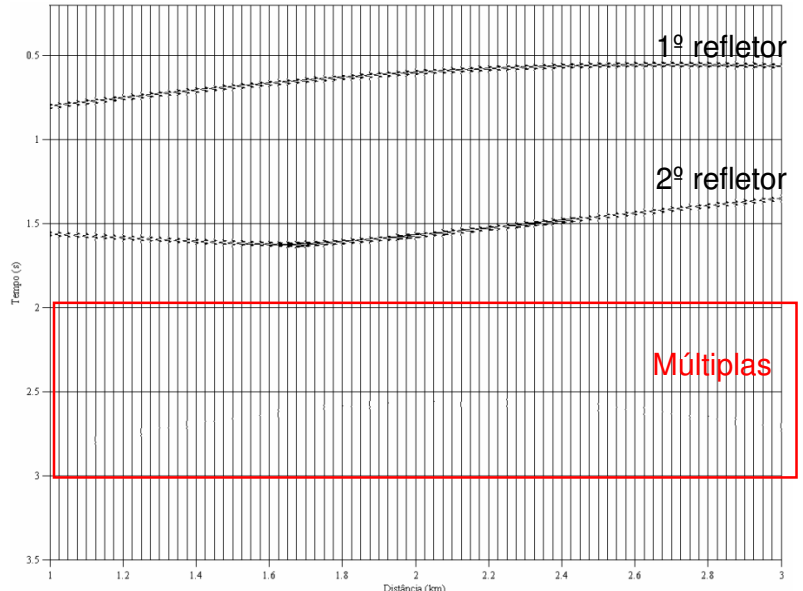

Figura 3 - Seção ZO obtida através do traçamento de raios com o software SEIS88 (Modelo I) apresentando reflexões múltiplas destacadas pelo retângulo vermelho.

Ao aplicar as aproximações CRS de $2^{\underline{a}}$ e $4^{\mathrm{a}}$ ordem foram obtidas a seções simuladas. Podemos observar a presença das reflexões primárias e das reflexões múltiplas geradas na segunda camada. Ambas as aproximações CRS de $2^{\underline{a}}$ e $4^{\underline{a}}$ ordem apresentam um bom desempenho na simulação de eventos de reflexões primárias e múltiplas.

Comparando a seção ZO original coma as seções CRS de $2^{\underline{a}}$ ordem e $4^{\underline{a}}$ ordem (Figura 4 e 5), observamos um bom desempenho na simulação dos eventos, tanto de reflexões primárias quanto de reflexões múltiplas. Desta forma, nota-se uma boa definição dos refletores e uma boa aproximação da seção original.

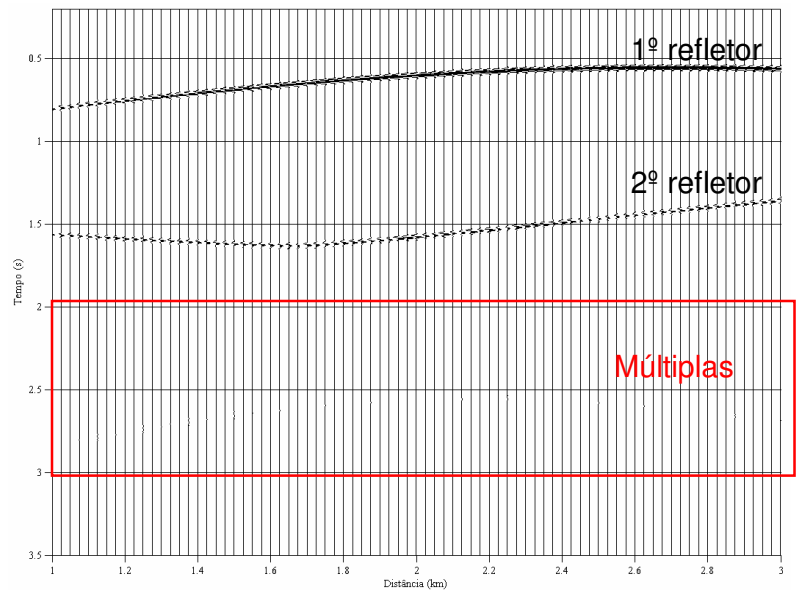

Figura 4 - Seção ZO simulada utilizando a aproximação CRS de $2^{a}$ ordem. As reflexões múltiplas com uma amplitude muito baixa são apresentadas no retângulo vermelho.

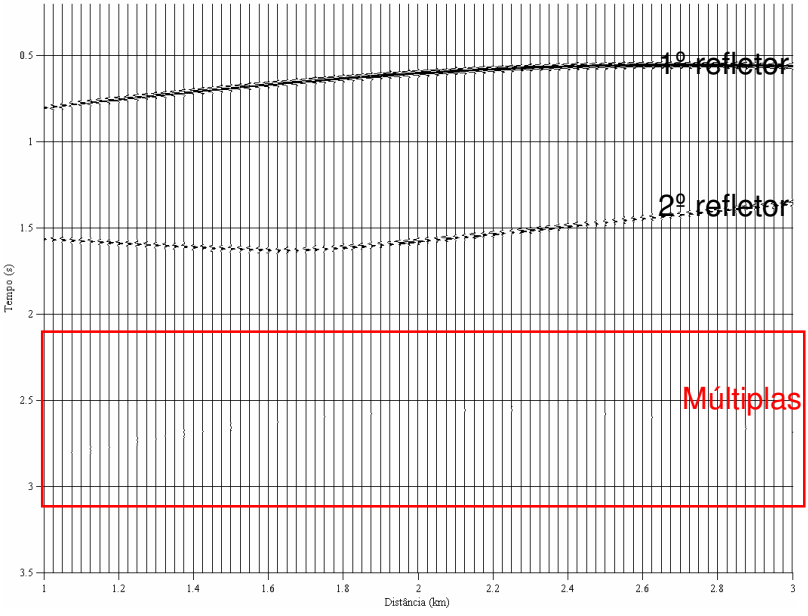

Figura 5 - Seção ZO simulada utilizando a aproximação CRS de $4^{a}$ ordem. As reflexões múltiplas com uma amplitude muito baixa são apresentadas no retângulo vermelho.

Nas figuras a seguir, com a finalidade de destacar melhor as múltiplas simuladas nas seções ZO (original e empilhadas) são apresentadas estas reflexões através de um zoom ampliado (ver Figuras 6, 7 e 8). No caso dos empilhamentos CRS de $2^{\underline{a}}$ e $4^{\text {a }}$ ordem, as múltiplas imageadas não diferem muito nos resultados.

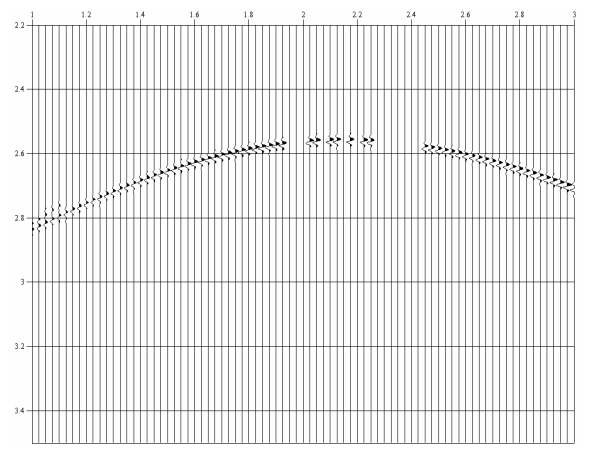

Figura 6 - Trecho destacado em vermelho da Figura 3 destacando as reflexões múltiplas obtidas pelo traçamento de raios com o software SEIS88.

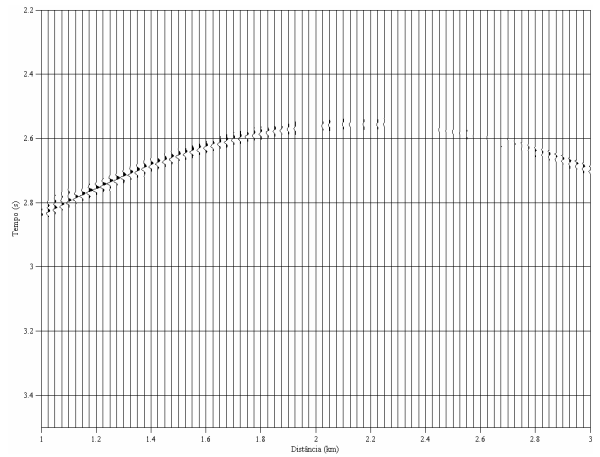

Figura 7 - Trecho destacado em vermelho da Figura 4 destacando as reflexões múltiplas simuladas com a aproximação CRS 2-D de $2^{\underline{a}}$ ordem. 


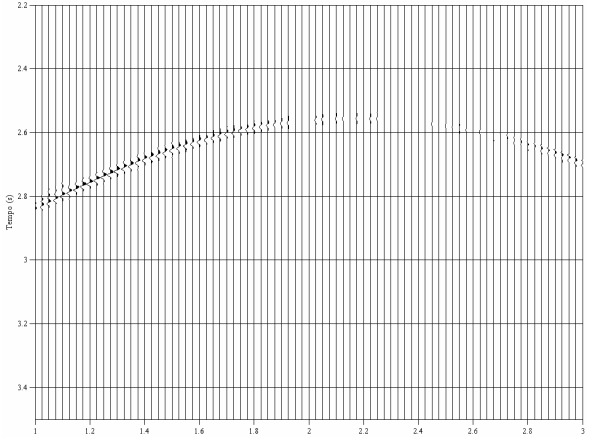

Figura 8 - Trecho destacado em vermelho da Figura 5 destacando as reflexões múltiplas simuladas com a aproximação CRS 2-D de 4ª ordem.

Na Figura 9 apresenta-se uma comparação entre os traços ZO original correspondente à coordenada do ponto médio, $x=1.225 \mathrm{~km}$, e os traços ZO obtidos a partir do empilhamento CRS de $2^{\underline{a}}$ e $4^{\underline{a}}$ ordem, respectivamente. Ambos os métodos apresentam um bom desempenho na simulação deste traço ZO, mas não são preservadas as amplitudes

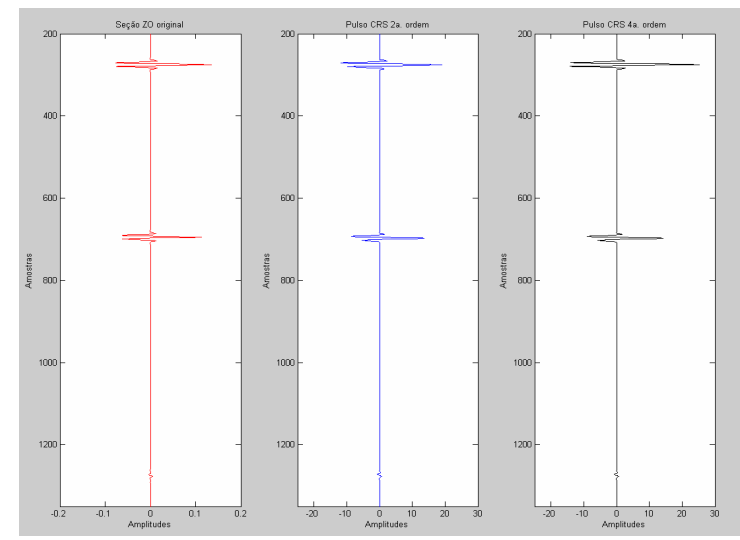

Figura 9 - Comparação dos traços sísmicos empilhados (modelo da Figura 2) correspondentes à posição do raio normal (central) em $x_{0}=1.225 \mathrm{~km}$, da seção de afastamento-nulo (ZO), seção empilhada CRS de $2^{\underline{a}}$ e $4^{\underline{a}}$ ordem.

\section{Modelo II}

O segundo modelo 2-D considerado neste estudo está constituído por três camadas homogêneas sob um semiespaço e separadas por interfaces curvas e suaves (Figura 10). As velocidades para cada camada, desde 0 topo até a base, são: $3.5 \mathrm{~km} / \mathrm{s}, 2.5 \mathrm{~km} / \mathrm{s}, 4.5 \mathrm{~km} / \mathrm{s}$ e 5.5 $\mathrm{km} / \mathrm{s}$. As dimensões do modelo são: $3 \mathrm{~km}$ de comprimento por $3.0 \mathrm{~km}$ de profundidade. A simulação de aquisição foi realizada considerando uma linha horizontal.

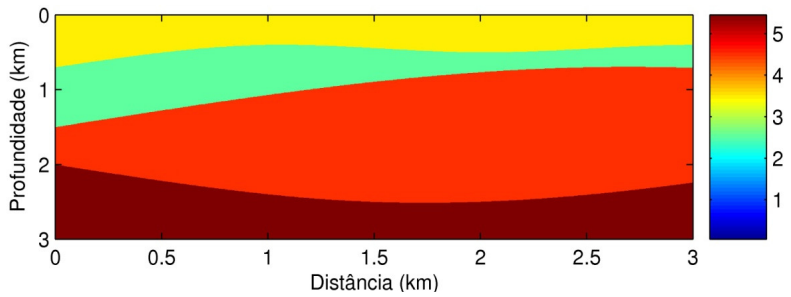

Figura 10 - Modelo 2-D constituído por três camadas separadas com interfaces curvas e suaves sob um semiespaço.

Baseado neste modelo foi gerado o conjunto de dados sintéticos de reflexão de cobertura múltipla utilizando o algoritmo de traçamento de raio, SEIS88 (Cerveny e Psensik, 1988). Os dados não contêm ruído e foram gerados utilizando a configuração common-shot (CS) ou de tiro comum. O mínimo e máximo afastamento foram $0.6 \mathrm{~km}$ e $2.9 \mathrm{~km}$, respectivamente.

Ao aplicar as aproximações CRS de $2^{\underline{a}}$ e $4^{\mathrm{a}}$ ordem foram obtidas a seções simuladas (ver Figuras 12 e 13). Podemos observar a presença das reflexões primárias e das reflexões múltiplas geradas na terceira camada. Ambas as aproximações CRS de $2^{\underline{a}}$ e $4^{\text {a }}$ ordem apresentam um bom desempenho na simulação de eventos de reflexões primárias e múltiplas.

Comparando a seção ZO original com as obtidas pelas aproximações CRS de $2^{\underline{a}}$ e $4^{\text {a }}$ ordem, observa-se uma boa definição dos refletores e uma boa aproximação da seção original.

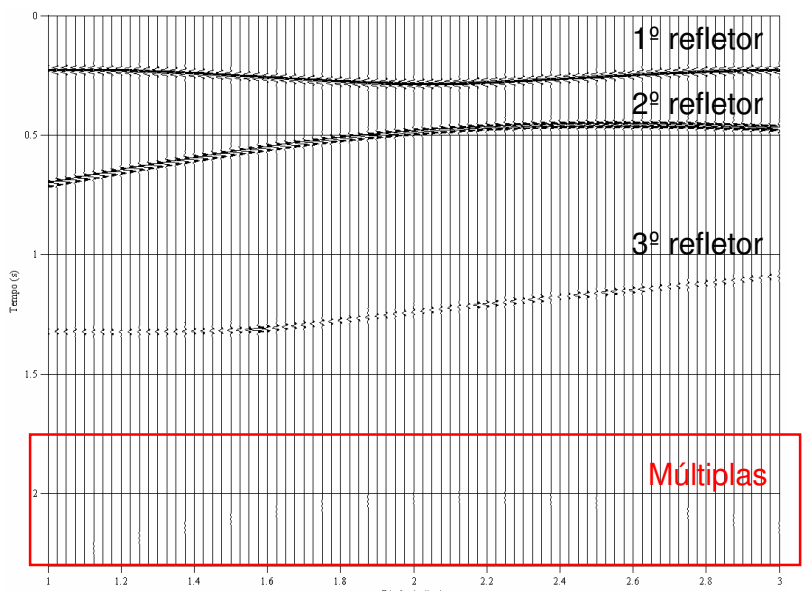

Figura 11 - Seção ZO (zero-offset) obtida através do traçamento de raios com 0 software SEIS88 apresentando as reflexões primárias e múltiplas (destacados no retângulo em vermelho). 


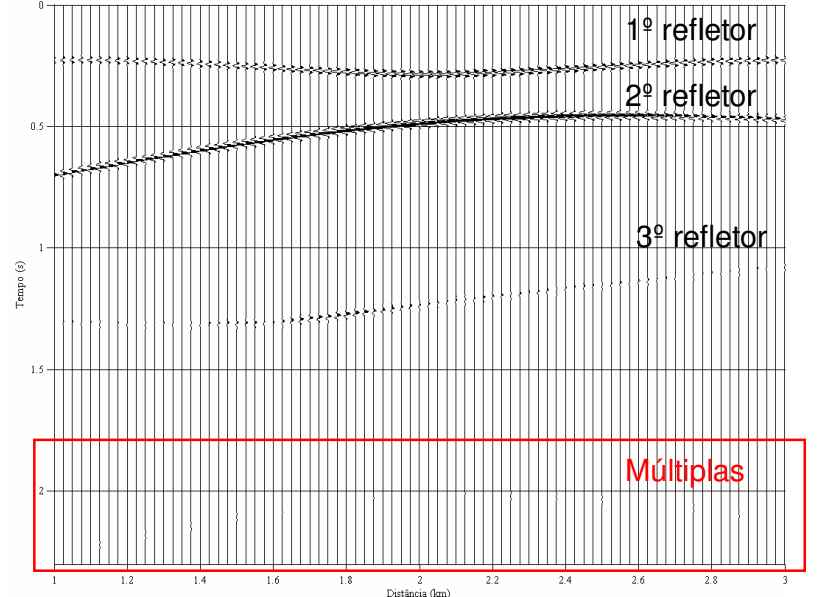

Figura 12 - Seção ZO simulada utilizando a aproximação CRS de $2^{a}$ ordem. As reflexões múltiplas com uma amplitude muito baixa são apresentadas no retângulo vermelho.

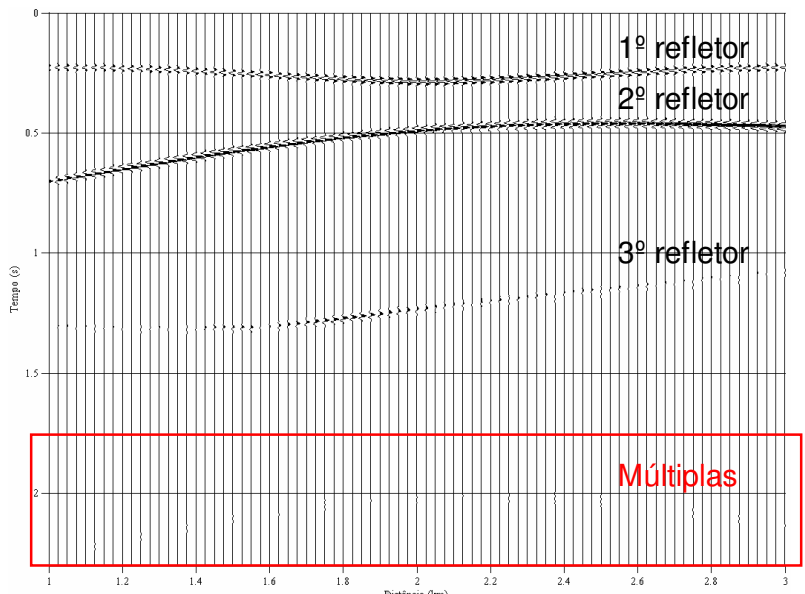

Figura 13 - Seção ZO simulada utilizando a aproximação CRS de $4^{a}$ ordem. As reflexões múltiplas com uma amplitude muito baixa são apresentadas no retângulo vermelho.

Nas Figuras a continuação, com a finalidade de destacar melhor as múltiplas simuladas nas seções ZO (original e empilhadas) são apresentadas estas reflexões através de um zoom ampliado (ver Figuras 14, 15 e 16). No caso dos empilhamentos CRS de $2^{\underline{a}}$ e $4^{\underline{a}}$ ordem, as múltiplas imageadas não diferem muito nos resultados.

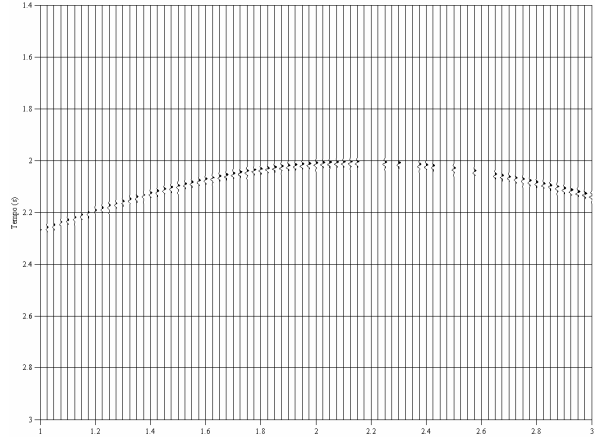

Figura 14 - Trecho destacado em vermelho da Figura 11 destacando as reflexões múltiplas obtidas pelo traçamento de raios com o software SEIS88.

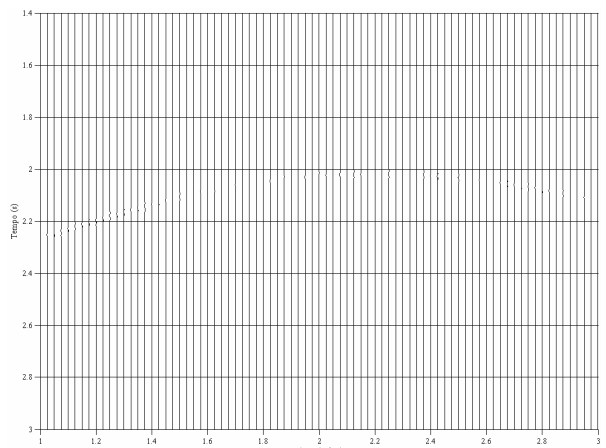

Figura 15 - Trecho destacado em vermelho da Figura 12 destacando as reflexões múltiplas simuladas com a aproximação CRS 2-D de $2^{a}$ ordem.

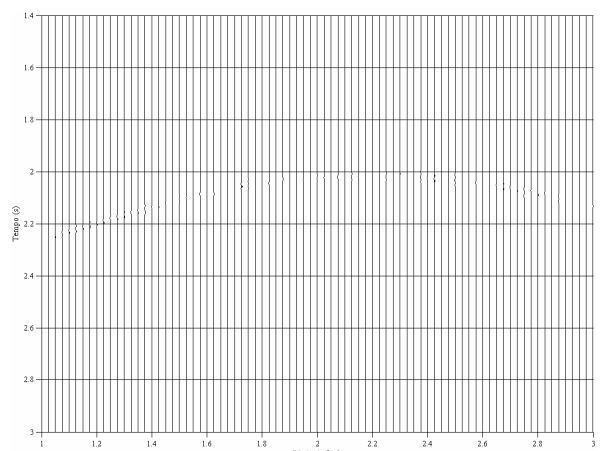

Figura 16 - Trecho destacado em vermelho da Figura 13 destacando as reflexões múltiplas simuladas com a aproximação CRS 2-D de 4ª ordem.

$\mathrm{Na}$ Figura 17 é apresentada uma comparação entre o traço ZO original correspondente à coordenada do ponto médio, $x=1.225 \mathrm{~km}$, e os traços $Z O$ obtidos a partir do empilhamento CRS de $2^{\mathrm{a}}$ e $4^{\mathrm{a}}$ ordem, respectivamente. Ambos os métodos apresentam um bom desempenho na simulação da seção ZO, mas não preservam as amplitudes. 


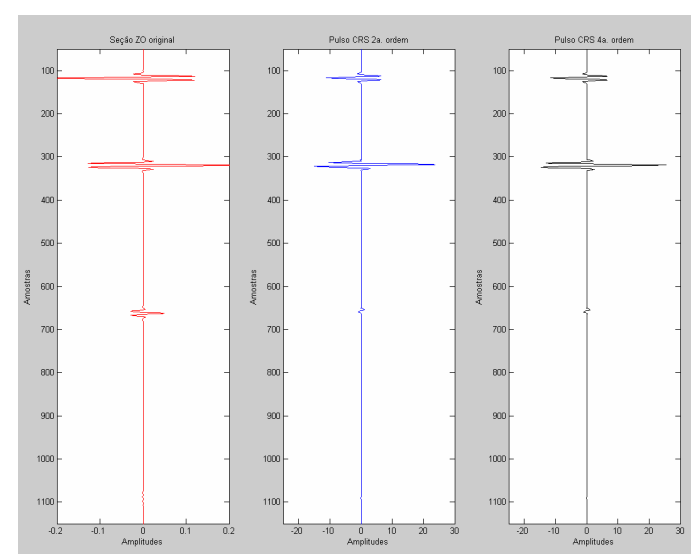

Figura 17 - Comparação dos traços sísmicos empilhados (modelo da Figura 7.8) correspondentes à posição do raio normal (central) em $x_{0}=1.25 \mathrm{~km}$, da seção de afastamento-nulo (ZO), seção empilhada CRS de $2^{a}$ e $4^{\underline{a}}$ ordem.

\section{Conclusões}

Como conseqüência deste trabalho pode-se concluir o seguinte:

- A aproximação de tempos de trânsito CRS de $4^{\text {a }}$ ordem simula satisfatoriamente seções de afastamento-nulo tanto quanto a aproximação de tempos de trânsito CRS de $2^{\underline{a}}$ ordem. Segundo os resultados obtidos podemos observar um bom posicionamento dos tempos de trânsito e uma boa visualização dos referidos eventos;

- Podemos notar que não há diferença de imageamento entre as duas aproximações (CRS de $2^{\underline{a}}$ e $4^{\underline{a}}$ ordem) quando 0 máximo afastamento fonte-receptor menor que $6 \mathrm{~km}$,

- O método CRS 2-D de $4^{a}$ ordem apresenta-se como uma importante alternativa para simular seções ZO (Zero-Offset) contendo reflexões múltiplas e primárias no caso de afastamentos longos.

\section{Referências}

CABRAL, R. Simulação de reflexões múltiplas usando o método de empilhamento sísmico Superfície de Reflexão Comum. 2002.44f. Dissertação (mestrado em geofísica) Universidade Federal do Pará, Instituto de Geociências, Curso de Pós-Graduação em Geofísica, Belém, 2002.

ČERVENÝ, V.; PSENCIK, I. SEIS88, Ray Tracing Program Package.INSTITUTE OF GEOPHYSICS. CHARLES UNIVERSITY, CZECHOSLOVAKIA,1988.

CHIRA OLIVA, P.A.; CRUZ, J. C. R.; CARDOS, M. Fourth order CRS stack: synthetic examples. Wave Inersion Tecnology: WIT Report (Alemanha), 2008. p. 53-60.
CHIRA OLIVA, P.A.; GARABITO, G.; CRUZ, J. C. R.Fourth-Order Stacking Method - Examples. In: EAGE CONFERENCE \& EXHIBITION INCORPORATING SPE EUROPEC, $72^{\text {nd }}, 2010$, Barcelona, Poster Session, $p$. 557.

CHIRA-OLIVA, P.A.; TYGEL, M.; HUBRAL, P.; SCHLEICHER, J.A Fourth-order CRS moveout for reflection or diffraction events: numerical examples. Journal of Seismic Exploration, n. 12, p.197-219.2003.

GARABITO, G., CRUZ, J. C., HUBRAL, P., AND COSTA, J.Common reflection surface stack: $A$ new parameter search strategy by global optimization. In: SEG MTG,71th.2001, San Antonio,Texas. Expanded abstracts.San Antonio,Texas, USA, 2001.

HÖCHT, G., DE BAZELAIRE, E., MAJER, P. AND HUBRAL, P.Seismic and optics: hyperbolae and curvatures. RevitacientíficaJournal of Seismic Exploration, 12, p. 261-282.1999.

HUBRAL, P.Computing true reflexions in a laterally inhomogeneous earth.Geophysics, n.48, p.10511062.1983.

HUBRAL, P.Macro-model independent seismic reflection imaging. Journal of Applied Geophysics, Special Issue, n. 42, p.137-346.1999.

JÄGER, R.; MANN, J.; HÖCHT, G. ; HUBRAL, P., 2001.Common reflection surface stack: image and attributes. Geophysics, 66: 97-109.

MANN, J.; JÄGER, R.; MÜLLER, T.; HÖCHT, G. HUBRAL, P.Common-reflection-surface stack - a real data example. Journal of Applied Geophysics, v.42, p.301-318.1999.

MÜLLER,T., JÄGER, R., HÖCHT, G.Common Reflection Surface StackingMethod-Imaging with an unknownvelocity model.In: ANNUAL INT. MTG.,68. Expanded Abstracts, Soc. Expl. Geophys., p. 17641767.1998.

SCHLEICHER, J.; TYGEL, M.; HUBRAL, P.Parabolic and hyperbolic paraxial two pointstraveltimes in 3D media.Geophysical Prospecting, n.41, p.495-513.1993.

TYGEL, M.; MÜLLER, T.; HUBRAL, P.; SCHLEICHER, J.Eigenwave based multiparametertraveltime expansions. In: ANNUAL MTG. OF THE SOCIETY OF EXPLORATION GEOPHYSICISTS, 67th, Dallas. Expanded Abstracts, Dallas, 1997.. p.1770-1773. 